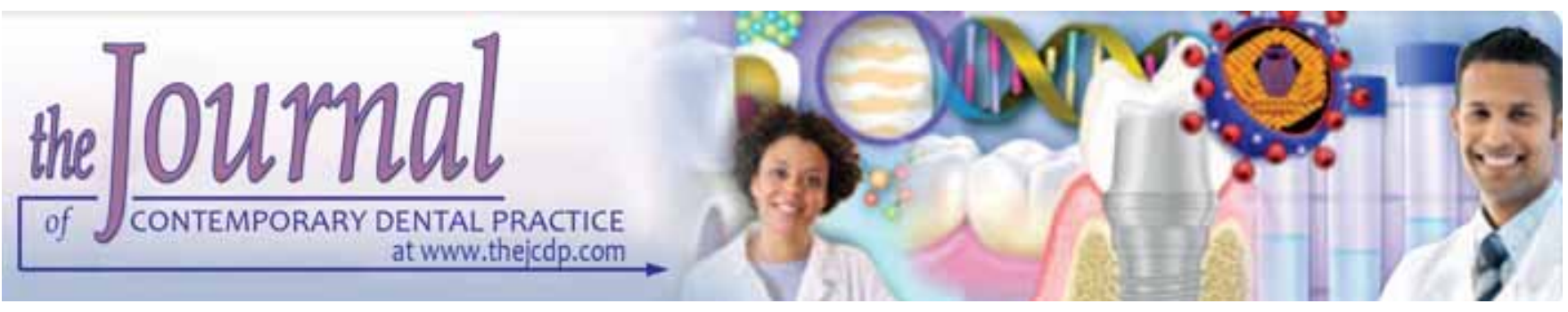

\title{
The Free Rotated Papilla Autograft-A Bilaminar Procedure for the Coverage of Multiple Shallow Gingival Recessions: A Biometric Evaluation
}

Vijay Prasad Koganti, L Chandrashekhar, SD Srinivas, M Kiran Kumar

\section{ABSTRACT}

The present clinical study was attempted to evaluate biometrically the predictability of free rotated papilla autograft for multiple shallow gingival recessions.

Materials and methods: Fifteen systemically healthy patients with multiple gingival recessions underwent the procedure the probing depth, percentage of root coverage width of keratinized gingiva, width of attached gingiva were recorded at baseline 3 and 12 months.

Results: All parameters significantly improved from baseline to 12 months. The mean probing depth $1 \mathrm{~mm} \pm 0 \mathrm{~mm}$ at baseline which was increased to $1.175 \pm 0.245 \mathrm{~mm}$ at the end of 3 months and remained same at 12 months. The mean gingival recession was $2.35 \pm 0.516 \mathrm{~mm}$ at baseline which was improved to 0.425 $\pm 0.245 \mathrm{~mm}$ at the end of 3 months and remained same at 12 months. The mean width of keratinized gingiva was $1.157 \pm$ $0.245 \mathrm{~mm}$ at baseline which was improved to $3.15 \pm 0.489 \mathrm{~mm}$ at the end of 3 months and remained same at 12 months. The mean width of attached gingiva $0.175 \pm 0.245 \mathrm{~mm}$ at baseline which was improved to $1.975 \pm 0.415 \mathrm{~mm}$ at the end of 3 months and remained same at 12 months.

Conclusion: The mucogingival surgery resulted in achieving high degree of success and predictability as well as an excellent esthetic outcome.

Clinical significance: Free rotated papilla autograft is a predictabe treatment modality for multiple shallow gingival recessions.

Keywords: Free rotated papilla autograft, Multiple shallow gingival recessions.

How to cite this article: Koganti VP, Chandrashekhar L, Srinivas SD, Kumar MK. The Free Rotated Papilla AutograftA Bilaminar Procedure for the Coverage of Multiple Shallow Gingival Recessions: A Biometric Evaluation. J Contemp Dent Pract 2011;12(4):245-251.

Source of support: Nil

Conflict of interest: None declared

\section{INTRODUCTION}

A smile is one of the most primitive forms of human communication and it is not surprising that an esthetic one is the major ambition to the patients.

Gingival recession often a source of anxiety to the patients and perplexity to those treating them is an intriguing and complex phenomenon.

Patients with gingival recession usually complain about tooth sensitivity and an unacceptable esthetics of the involved area.

The periodontist concern is different. Associated with recession, they often find an absence of the attached gingiva which renders the area vulnerable to inflammation root caries and hypersensitivity, ${ }^{1,2}$ which may develop on the denuded cemented surface leading to pulpoperiodontal problem.

There are various techniques to cover the isolated gingival recession to single tooth but very few techniques have been described in the literature to cover the multiple recessions associated with a group of teeth. Carlotinti and Parma-Benfananti ${ }^{3}$ described mucogingival grafting procedure that has been developed to completely cover the multiple gingival recessions.

In the light of increasing knowledge on reconstructive mucogingival surgery for the correction of gingival recessions, the present study is therefore an attempt to evaluate biometrically the predictability of free rotated papillae autograft to cover the multiple denuded root surfaces.

Treatment of defects first concern the arrest of any etiological factors (Table 1): ${ }^{4}$ Success relies on choosing suitable cases to treat. Miller classified recession based on 
Table 1: Factors that cause recession

- High frenum or muscle attachment

- Thin gingiva and bone

- Prominent or malpositioned teeth

- Orthodontic movement

- Subgingival restorations

- Periodontal disease

- Abrasion

- Toothbrush

- Erosion

- Periodontal therapy

- Scaling and root planing in shallow pockets

- Respective surgery

Snuff use

- Foreign body impaction

- Peri- and intraoral piercings

the relationship between the soft and hard tissues and more importantly correlated each level of recession to an estimated percentage of root coverage (Table 2). ${ }^{5}$ In essence, the higher the level of interproximal bone, the better result.

\section{MATERIALS AND METHODS}

\section{Patient Selection}

Fifteen nonsmoker patients aged between 20 and 50 years who required root coverage either for esthetics or for treatment of sensitivity had been undertaken in this study. Patients were selected with excellent general medical health and no systemic contraindication to surgical treatment. The etiology of these multiple recessions was either due to plaque-induced gingival inflammation or incorrect brushing technique. All the patients received meticulous scaling, curettage and root planing prior to surgical therapy. The teeth with prominent root convexities were planed to reduce the convexities. Occlusal premature contacts checked and eliminated. A thorough plaque control program was initiated for each patient including instructions in brushing technique (modified stillman). The presence of supragingival plaque and degree of gingival inflammation were recorded by Turesky-Gilmore-Glickman modification of Quigley-Hein plaque index ${ }^{6}$ and Ramjford gingival index ${ }^{7}$ respectively in every patient throughout the study period. The patients selected were informed of the treatment options and received written consent from all the patients.
Mucogingival recessions were selected on the basis of the following anatomic considerations proposed by Carlotinti and Parma-Benfananti: ${ }^{3}$

1. The width and depth of gingival recession were $\leq 5 \mathrm{~mm}$.

2. Interproximal bone crests showed no periodontal lesion clinically and no bone loss radiographically.

3. It was necessary to have thick wide interproximal papillae not smaller than the recession defect and devoid of any anatomical defect such as deep gingival groove.

4. It was not necessary to have residual keratinized tissue associated with the defect.

5. Deep gingival grooves were not present on the donor papillae.

\section{Clinical Measurements}

The following measurements were taken at the midfacial surfaces of teeth to be treated with the Williams periodontal probe to the nearest $0.5 \mathrm{~mm}$ using cementoenamel junction as fixed point, one week before surgery (baseline) and repeated at 3 and 12 months postoperatively.

1. Extent of coverage of recession

2. Depth of gingival sulcus

3. Width of keratinized gingiva

4. Width of attached gingiva.

\section{Surgical Technique}

The area to be operated was anesthetized both facially and lingually using 2\% xylocaine with 1:200,000 adrenaline, by submucosal infiltration anesthesia (Fig. 1).

The preparation of the recipient bed was initiated by a sharp incision performed at a $90^{\circ}$ angle to the vestibule following the mucogingival line using 15 No BP blade and extended in a mesiodistal direction to completely include the mesial and distal papillae adjacent to the gingival recession that needs to be treated (Fig. 2).

Sharp dissection was accomplished to create a partial thickness envelope flap on the underlying alveolar mucosa. The muscle fibers were dissected with a coronoapical direction of the blade well beyond the mucogingival junction

Table 2: Miller's classification of marginal tissue recession 


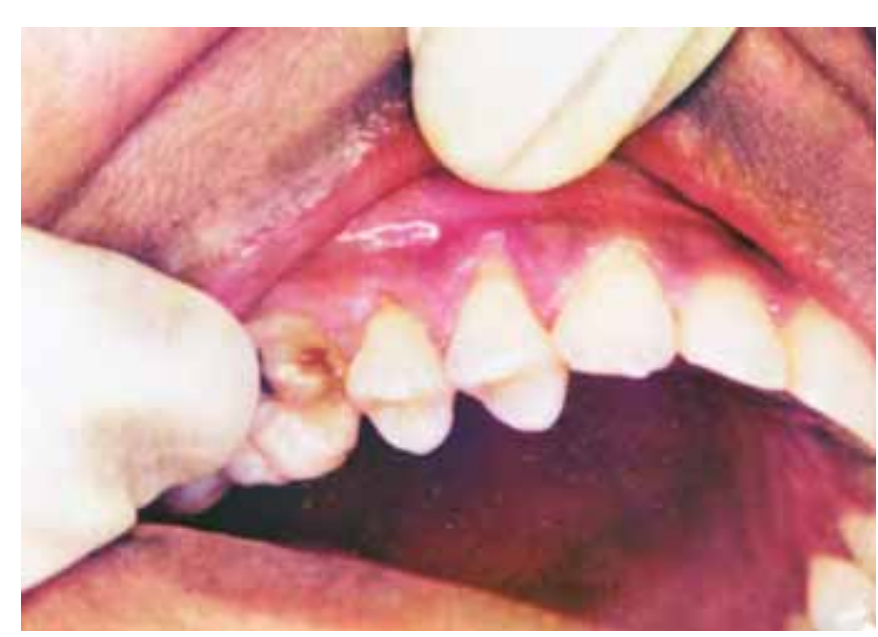

Fig. 1: Gingival recessions before surgery

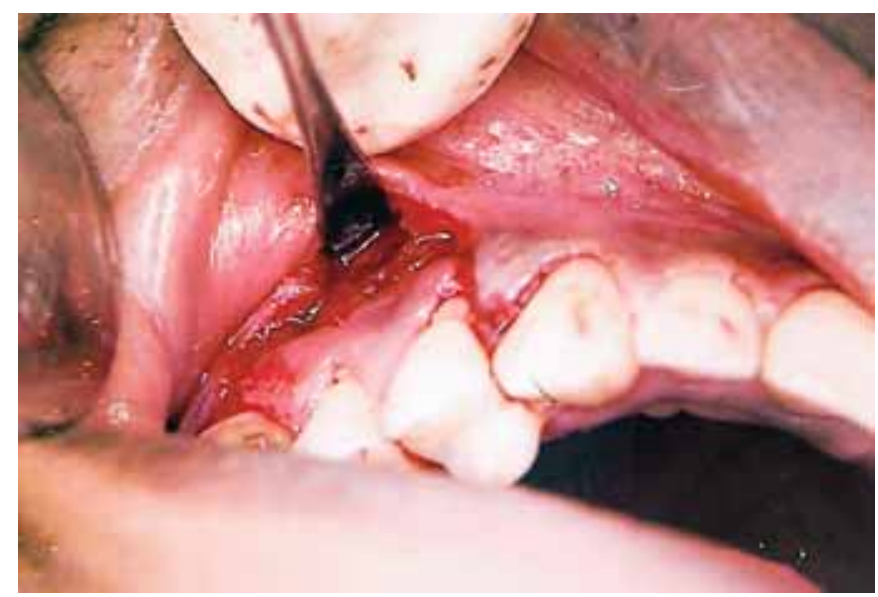

Fig. 2: Initial horizontal right angle incision following mucogingival line

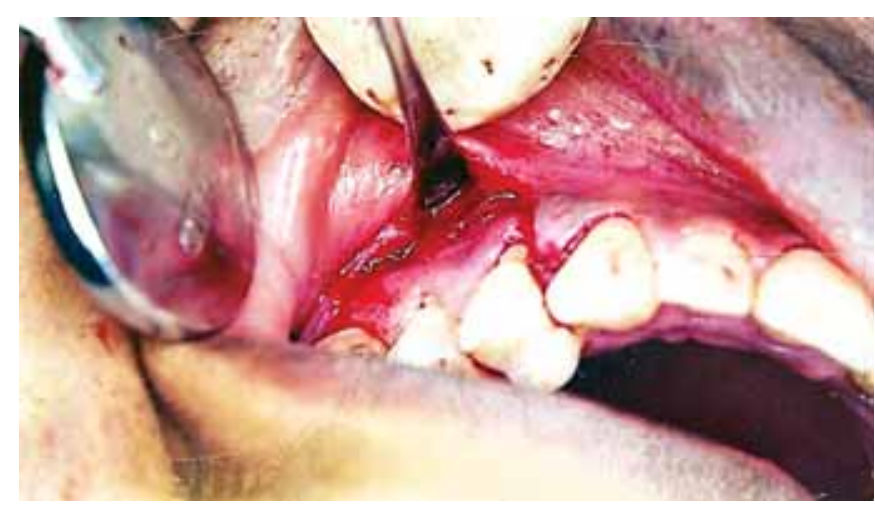

Fig. 3: Reflection of partial thickness flap by sharp dissection

for approximately 10 to $12 \mathrm{~mm}$ in order to reflect a partial thickness flap on the facial aspect only (Fig. 3).

The epithelium from the facial aspect of the papillae adjacent to the area of recession was debrided with a rotary diamond bur under copious sterile saline irrigation (Fig. 4).

The exposed root surfaces were root planed with curette to remove bacterial contamination and rotary instruments to reduce the convexities.
A third incision was made beginning at the first incision utilizing 15 No BP blade and extended coronally, maintaining a full thickness of facial papillary tissue.

This band of tissue containing the papilla was removed from the underlying tissue bed, by sharp dissection (Fig. 5).

The papillae were then reversed in such a manner that their bases were at cementoenamel junction and apices at the base of the area of gingival recessions.

The papillae were then sutured on recipient periosteal bed utilizing restorable 5-0 suture by horizontal crossed mattress suturing technique (Fig. 6).

In order to improve vascularization and also to facilitate the healing process, the previously raised partial thickness envelope flap was then coronally positioned to a point where it had completed the rotated papillae graft and was secured into this new position utilizing nonrestorable 4-0 suture by interdental interrupted suturing technique (Fig. 7).

Slight firm pressure with saline-soaked gauze was applied for 5 minutes to gain the initial adaptation of the flap and graft to the underlying tissue to avoid dead spaces. A periodontal surgical dressing was placed to protect the wound for approximately 8 days. An ice pack was applied

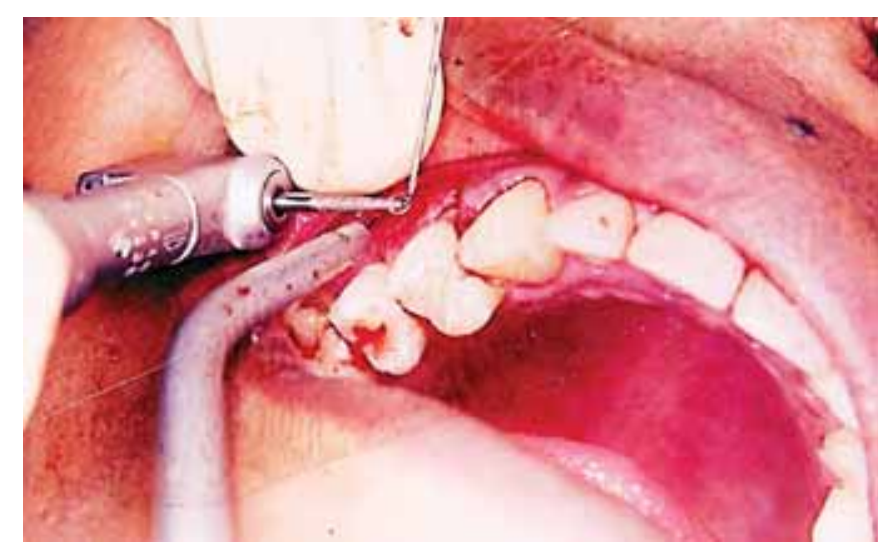

Fig. 4: De-epithelization of interdental papillae under saline irrigation

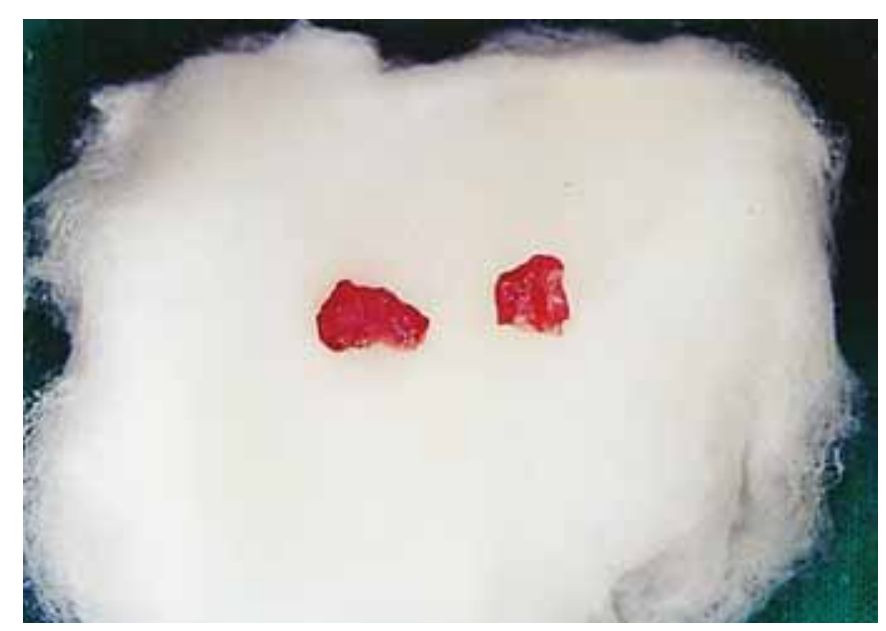

Fig. 5: Free connective tissue grafts 


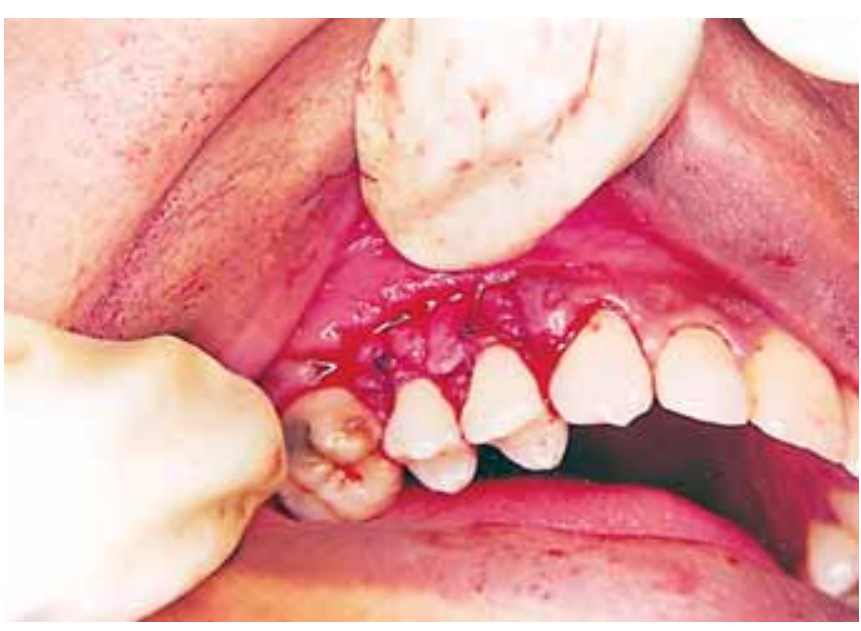

Fig. 6: Rotated papillae connective tissue grafts sutured at recepient site by horizontal mattress crossed suture

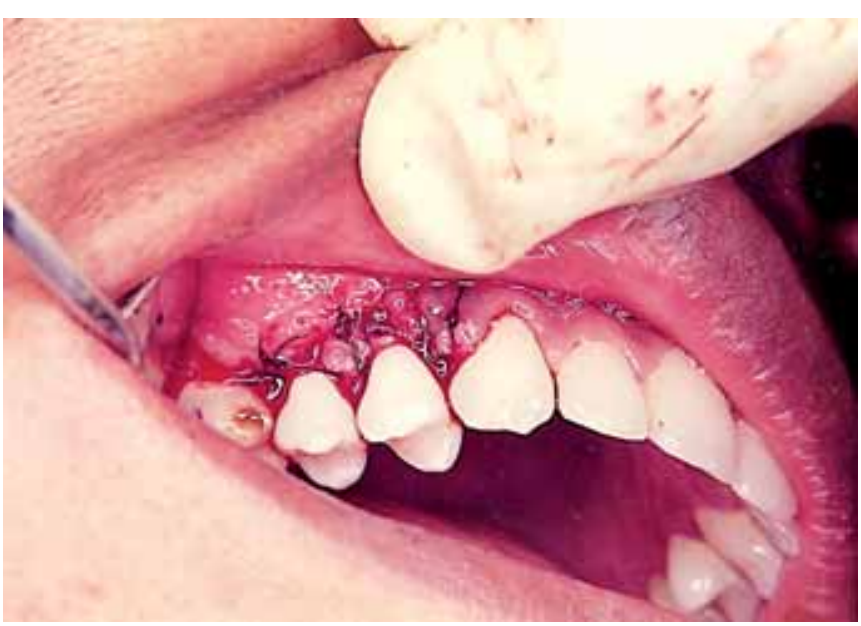

Fig. 7: Partial thickness coronally positioned flap sutured over connective tissue graft

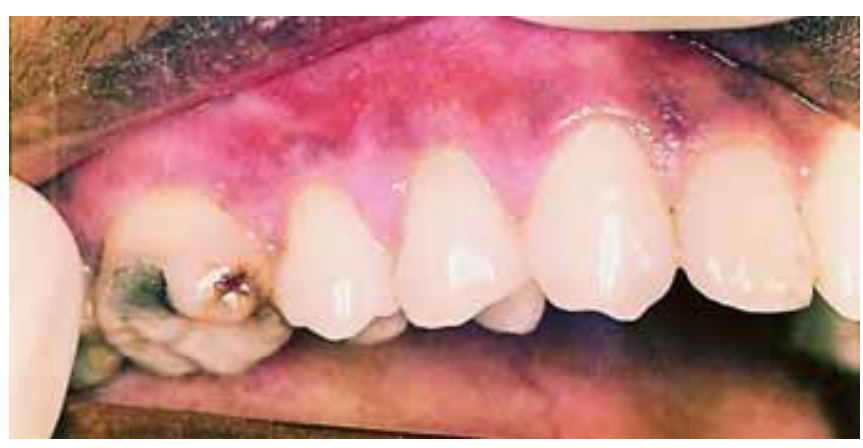

Fig. 8: Three months postoperative

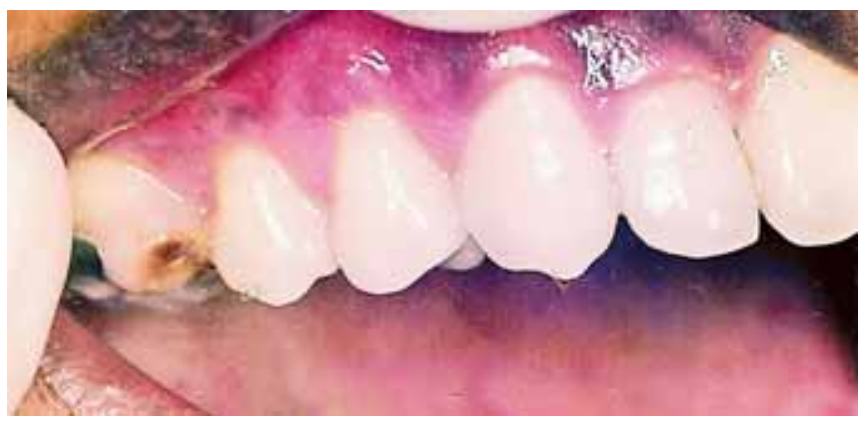

Fig. 9: Twelve months postoperative in order to avoid undesired swelling. Antibiotic therapyAmoxicillin $0.5 \mathrm{gm} \times 3$ was prescribed for 6 days

Chemical plaque control with chlorhexidine mouthwash $2 \times 1$ minute per day was prescribed for 14 days. After the first week, the periodontal surgical dressing was removed and the operated area was gently debrided with a cotton swab and saline irrigation and the pack was replaced for 7 days.

Sutures were left in place for another week and both the periodontal pack and nonresorbable sutures were removed at the end of 14 days. Tooth brushing was discontinued for the first 2 weeks in the surgical site. The surgical area was seen postoperatively at the end of 3 and 12 months (Figs 8 and 9).

\section{Statistical Analysis}

All data obtained were analyzed biometrically and were subjected to statistical analysis to determine the significance of the results.

1. Paired t-test: For statistical significance of comparison of preoperative to postoperative values, Student's paired t-test was used

$$
\begin{aligned}
\operatorname{td}_{\mathrm{f}} & =\frac{\overline{\mathrm{X}} \mathrm{d}}{\alpha \mathrm{d} / \sqrt{\mathrm{n}}} \\
\overline{\mathrm{X}} \mathrm{d} & =\text { The mean difference } \\
\alpha \mathrm{d} & =\text { SD of difference } \\
\mathrm{n} & =\text { Sample size } \\
\mathrm{d}_{\mathrm{f}} & =\text { Degree of freedom }(\mathrm{n}-1)
\end{aligned}
$$

2. Standard deviation: The standard deviation is a summary measure of the difference of each observation from the mean

$$
\begin{aligned}
\mathrm{SD} & =\sqrt{\frac{\sum(\mathrm{X}-\overline{\mathrm{X}})^{2}}{\mathrm{n}-1}} \\
\overline{\mathrm{X}} & =\text { Mean } \\
\mathrm{n} & =\text { Sample size }
\end{aligned}
$$

\section{RESULTS}

The free-rotated papillae autograft was performed on 15 patients for the correction of multiple shallow gingival recessions with absence of attached gingiva. The 30 areas of recessions treated on 15 patients showed the following distribution of teeth, 16 maxillary premolar teeth, 4 maxillary canines, 4 maxillary lateral incisors and 6 mandibular premolar teeth. The patients maintained a good standard of supragingival plaque control throughout the study period. No adverse events were recorded during the postoperative period. The mean values of variables measured at baseline, 3 and 12 months after surgery are summarized in Table 3. 


\section{Gingival Sulcus/Probing Depth}

The mean probing depth was $1 \mathrm{~mm} \pm 0 \mathrm{~mm}$ at baseline which was increased to $1.175 \mathrm{~mm} \pm 0.245 \mathrm{~mm}$ at the end of 3 months and remained same at 12 months. The mean difference of $0.175 \mathrm{~mm} \pm 0.245 \mathrm{~mm}$ which was statistically less significant $(\mathrm{p}<0.05)(\mathrm{t}=2.254)$.

\section{Gingival Recession/Root Coverage}

The mean gingival recession was $2.35 \mathrm{~mm} \pm 0.516 \mathrm{~mm}$ at baseline which was reduced to $0.425 \mathrm{~mm} \pm 0.245 \mathrm{~mm}$ at end of 3 months and still remained same at 12 months. The mean difference of $1.925 \mathrm{~mm} \pm 0.494 \mathrm{~mm}$ which was statistically very highly significant $(\mathrm{p}<0.001)(\mathrm{t}=15.07)$.

\section{Keratinized Gingiva}

The mean width of keratinized gingiva was $1.175 \mathrm{~mm} \pm$ $0.245 \mathrm{~mm}$ at baseline which was improved to $3.15 \mathrm{~mm} \pm$ $0.489 \mathrm{~mm}$ at the end of 3 months and remained same at 12 months. The mean difference of $1.975 \mathrm{~mm} \pm 0.472 \mathrm{~mm}$ which was statistically very highly significant $(\mathrm{p}<0.001)$ $(\mathrm{t}=16.15)$.

\section{Attached Gingiva}

The mean width of attached gingiva was $0.175 \mathrm{~mm} \pm$ $0.245 \mathrm{~mm}$ at baseline which was improved to $1.975 \mathrm{~mm} \pm$ $0.415 \mathrm{~mm}$ at the end of 3 months and remained same at 12 months. The mean difference of $1.775 \mathrm{~mm} \pm 0.499 \mathrm{~mm}$ which was statistically very highly significant $(\mathrm{p}<0.001)$ $(\mathrm{t}=16.70)$ (Table 3).

\section{DISCUSSION}

Recession of the marginal periodontal tissue over mainly the facial root surfaces is fairly a common finding.

The past 20 years has seen an explosion of interest in mucogingival surgery with accompanying visitors in surgical techniques to treat recession defects.
There are two main root coverage procedures:

1. Reconstructive flaps (known also as pedicle grafts)

2. Free grafts. ${ }^{8}$

Reconstructive flaps like lateral pedicle flap and double papillae pedicle flap uses the tissue adjacent to the receded area and still attached at the base to cover the defect.

This flapped mucosa may be rotated or simply advanced to obscure the recession. This may or may not involve papillae because there is a limit to the amount of available adjoining tissue and of lateral slide achievable, the rotation flap treats single-receded areas with relative care but multiple sites with difficulty.

A coronally advanced flap conversely uses the gingiva immediately apical to the recession and does not compromise tissue overlying adjacent roots permitting it to cover a more extensive region of recession. ${ }^{9-11}$

Alternatively, the clinician may prefer to isolate tissue from a secondary location. Compared with reconstructive flaps, free grafts usually provide more donor tissue but does not sustain a continuous blood supply. Free grafts, like FCG and connective tissue graft consist of autogenously or allergenic tissue. Harvested typically from host palate but occasionally other sites (e.g. edentulous ridges attached buccal gingiva) the free gingival graft possesses a full layer of surface epithelium, whereas connective tissue graft does not. ${ }^{12,13}$

Processed allograft from human dermis also serves as free source which bars the need for second surgical site and as it is collected from cadavers, has a virtually limitless supply. Even though case reports demonstrate high cosmetic success, the average root coverage of teeth treated with a cellular dermal matrix declined from 93 to $66 \%$ over the study period, this could be due to presence of elastic fibers that shrink. ${ }^{14}$

Some practitioners perform GTR in conjunction with coronally positioned flaps. Membranes either absorbable or nonabsorbable, impede epithelial down growth and this help to restablish the connective tissue attachment via site repopulation with cementoblasts, osteoblasts and

\begin{tabular}{|c|c|c|c|c|c|c|c|}
\hline S. no. & Parameters & $\begin{array}{c}\text { Baseline } \\
(\text { mean } \pm S D)\end{array}$ & $\begin{array}{c}3 \text { months } \\
(\text { mean } \pm \text { SD) }\end{array}$ & $\begin{array}{c}12 \text { months } \\
\text { (mean } \pm S D)\end{array}$ & $t$-value & $p$-value & $\begin{array}{l}\text { Statistical } \\
\text { analysis }\end{array}$ \\
\hline 1. & $\begin{array}{l}\text { Gingival } \\
\text { sulcus (mm) }\end{array}$ & $1 \pm 0$ & $1.175 \pm 0.245$ & $1.175 \pm 0.245$ & 2.254 & $p<0.05$ & $\begin{array}{l}\text { Less } \\
\text { significant }\end{array}$ \\
\hline 2. & $\begin{array}{l}\text { Gingival } \\
\text { recession (mm) }\end{array}$ & $2.35 \pm 0.516$ & $0.425 \pm 0.245$ & $0.425 \pm 0.245$ & 15.07 & $p<0.001$ & $\begin{array}{l}\text { Very highly } \\
\text { significant }\end{array}$ \\
\hline 3. & $\begin{array}{l}\text { Keratinized } \\
\text { gingiva }(\mathrm{mm})\end{array}$ & $1.175 \pm 0.245$ & $3.15 \pm 0.489$ & $3.15 \pm 0.489$ & 16.15 & $p<0.001$ & $\begin{array}{l}\text { Very highly } \\
\text { significant }\end{array}$ \\
\hline 4. & $\begin{array}{l}\text { Attached } \\
\text { gingiva (mm) }\end{array}$ & $0.175 \pm 0.245$ & $1.975 \pm 0.415$ & $1.975 \pm 0.415$ & 16.70 & $p<0.001$ & $\begin{array}{l}\text { Very highly } \\
\text { significant }\end{array}$ \\
\hline
\end{tabular}


periodontal ligament fibroblasts. ${ }^{15}$ In theory such an attachment creates long-term stability. Harris in contrast saw significant and rather rapid deterioration of early GTR results from 92\% mean coverage at 6 months to just $60 \%$ at 2 years. ${ }^{16}$ No randomized controlled trails exist to verify these findings.

Bone grafts may be used as an adjunct to membranes to encourage hard tissue regrowth over the recession defect though studies fail to show any added benefit from demineralized freeze dried bone allograft. ${ }^{17,18}$ Moreover, human histology presents minimal or inconsistent evidence of new bone and cementum from guided tissue regeneration. ${ }^{19}$

Accordingly, it is unfeasible to advocate use of membrane technology over traditional techniques, though it certainly remains available treatment option for deep and wide recessions ( $\geq 5 \mathrm{~mm}$ ).

To be sure there is a movement in periodontics to embrace the application of potentially regenerative materials to augment or even substitute for conventional therapy. This marks a conceptual evolution of the field from being anecdotally based to biologically rooted — a good thingbut at present no longitudinal proof exists to substantiate claims of true regeneration or clinical superiority. Currently, groups employ several major biometric or human derived products to improve root coverage with mixed or unexceptional results. ${ }^{20-25}$ This is not to say such materials do not work, there are promising scientific rationals for their function but they may require improved clinical formulations.

The free-rotated papillae autograft used in the present study has the potential to cover shallow multiple gingival recession $\leq 5 \mathrm{~mm}$ due to its bilaminar approach. The relation of the vascular periosteum on the recipient site and the overlying coronally positioned flap has resulted in a more rapid re-establishment of circulation within the free-rotated papillae autograft and contributed to more predictable and successful root coverage. Although this procedure is more delicate and technique sensitive, it offers the advantages like single surgical site, good color compatibility with adjacent tissue, minimum discomfort to the patient and healing by primary intention.

\section{CONCLUSION}

The present study has observed highly significant root coverage obtained 12 months postsurgically with minimum gain of $82 \%$ root coverage along with minimum gain of $2.0 \mathrm{~mm}$ attached gingiva. If I want a better smile is the chief complaint of the patient the practitioner must scrutinize not only the face, lips and teeth but also the periodontal drape. Restoration of ideal mucosal contours via root coverage is crucial to the design of pleasing smile. Keen diagnosis and elimination of receded areas may at times, transform a lifeless faces into a vibrant one and consequently, bolsters the patient's self-worth an incalculable award.

\section{REFERENCES}

1. Tungnait A, Clerehygh V. Gingival recession: Its significance and management. J Dent 2001;29:381-94.

2. Paolantonio M. Treatment of gingival recession by combined periodontal regenerative techniques, guided tissue regeneration, and subpedicle connective tissue graft: A comparative clinical study. J Periodontol 2002;73:53-62.

3. Tinti C, Parma-Benfenati S. The free rotated papilla autograft: A new bilaminar grafting procedure for the coverage of multiple shallow gingival recessions. J Periodontol 1996;67:1016-24.

4. Hall Walter B. Present status of soft tissue grafting. JP 1977;48:587.

5. Miller PD. A classification of marginal tissue recession. Int J Periodontics Restorative Dent 1985;5(2):8-13.

6. Turkesky S, Gilmore ND, Glickman I. Reduced plaque formation by the chloromethyle analogue of vit C. JP 1970;41:41.

7. Ramford SP. Indices for the prevalence and incidence of periodontal disease. JP 1961;30:51.

8. Bahat O, Handelsman M. Periodontal reconstructive flapsclassification and surgical considerations. Int J Periodontics Restorative Dent 1991;11(6):480-87.

9. Allen EP, Miller PD. Coronal positioning of existing gingiva: Short-term results in the treatment of shallow marginal tissue recession. J Periodontol 1989;60(6):316-19.

10. Bernimoulin JP, Luscher B, Muhleman HR. Coronally repositioned periodontal flap. Clinical evaluation after one year. J Clin Periodontol 1975;2(1):1-13.

11. Prato GP, Clauser C, Cortellini P. Periodontal plastic and mucogingival surgery. Periodontol 2000, 1995;9:90-105.

12. Sullivan HC, Atkins JH. Free autogenous gingival grafts. I. Principles of successful grafting. Peridontol 1968;6(3):121-29.

13. Langer B, Langer L. Subepithelial connective tissue graft technique for root coverage. J Periodontol 1985;56(12):715-20.

14. Gapski R, Parks CA, Wang HL. Acellular dermal matrix for mucogingival surgery: A meta-analysis. J Periodontol 2005; 76(11):1814-22.

15. Gottlow J, Nyman S, Lindhe J, et al. New attachment formation in the human periodontium by guided tissue regeneration. Case reports. J Clin Periodontol 1986;13(6):604-16.

16. Harris RJ. GTR for root coverage: A long-term follow-up. Int J Periodontics Restorative Dent 2002;22(1):55-61.

17. Al-Hamdan K, Eber R, Sarment D, et al. Guided tissue regeneration-based root coverage, meta-analysis. J Periodontol 2003;74(10):1520-33.

18. Oates TW, Robinson M, Gunsolley JC. Surgical therapies for the treatment of gingival recession. A systematic review. Ann Periodontol 2003;8(1):303-20.

19. Harris RJ. Histologic evaluation of root coverage obtained with GTR in humans: A case report. Int J Periodontics Restorative Dent 2001;21(3):240-51.

20. Huang LH, Neiva RE, Soehren SE, et al. The effect of plateletrich plasma on the coronally advanced flap root coverage procedure: A pilot humans: A case report. J Periodontol 2005;76(6):1768-77. 
21. Wilson TG, McGuire MK, Nunn ME. Evaluation of the safety and efficacy of periodontal applications of a living tissueengineered human fibroblast-derived dermal substitute. II. Comparison to the subepithelial connective tissue graft: A randomized controlled feasibility study. J Periodontol 2005;76(6):881-89.

22. McGurie MK, Scheyer ET. Comparison of recombinant human platelet-derived growth factor-BB plus beta tricalcium phosphate and a collagen membrane to subepithellial connective tissue grafting for the treatment of recession defects: A case series. Int J Periodontics Restorative Dent 2006;74(8):1110-25.

23. McGurie MK, Nunn M. Evaluation of human recession defects treated with coronally advanced flaps and either enamel matrix derivative or connective tissue (Part 1): Comparison of clinical parameters. J Periodontol 2003;74(8):1110-25.

24. McGurie MK, Cochran DL. Evaluation of human recession defects treated with coronally advanced flaps and either enamel matrix derivative or connective tissue (Part 2): Histological evaluation. J Periodontol 2003;74(8):1126-35.

25. Petrungaro PS. Using platelet-rich plasma to accelerate soft tissue maturation in esthetic periodontal surgery. Compend Contin Educ Dent 2001;22(9):729-46.

\section{ABOUT THE AUTHORS}

\section{Vijay Prasad Koganti (Corresponding Author)}

Professor, Department of Periodontics, Purvanchal Institute of Dental Sciences, Gorakhpur, Uttar Pradesh, India, e-mail: kogantivijay72@gmail.com

\section{Chandrashekhar}

Reader, Department of Periodontics, Purvanchal Institute of Dental Sciences, Gorakhpur, Uttar Pradesh, India

\section{SD Srinivas}

Professor, Department of Oral Surgery, MNR Dental College Sangareddy, Andhra Pradesh, India

\section{Kiran Kumar}

Reader, Department of Oral Surgery, Kalinga Institute of Dental Sciences, Bhubaneswar, Orissa, India 